\title{
III Conferencia
}

\section{Los aportes de Paulo Freire a la pedagogía crítica}

\author{
Moacir Gadotti
}

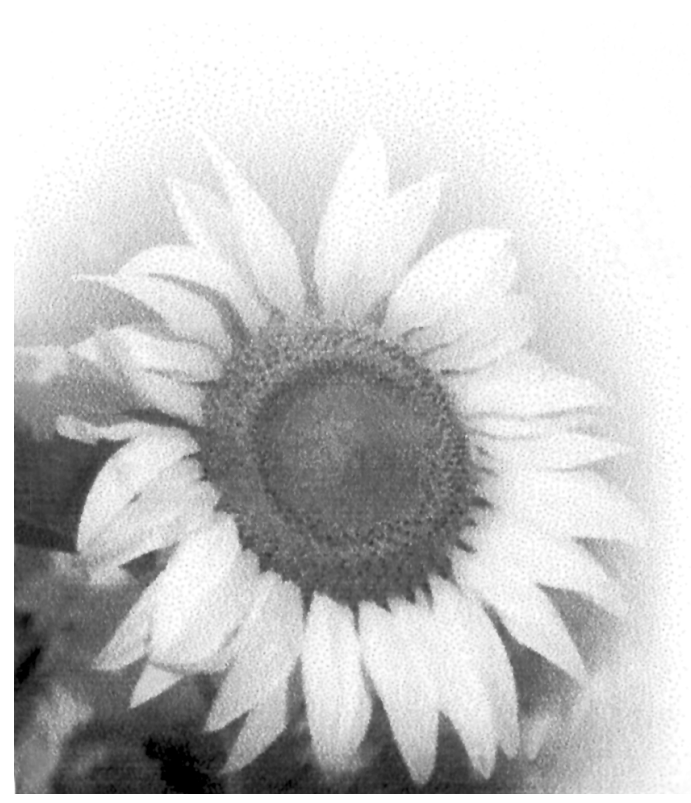

Paulo Freire não gostava de rotular as pedagogías, mas, desde que introduziu a tese de que existe uma educação como prática da domesticação e uma educação como prática da liberdade, podemos dizer que existe uma pedagogia dogmática, por conseguinte, domesticadora e uma pedagogia dialéctica, crítica, interrogativa. Paulo Freire foi um crítico da educação do seu tempo. Sua "pedagogia do oprimido" insere- se no grande movimento da "pedagogia crítica", também chamada de "radical" ou "revolucionária”, dependedo do contexto.

Muitos educadores, reunidos em "Círculos de Cultura", em Porto Alegre, de 25 a 30 de janeiro de 2001, durante o Fórum Social Mundial, com razão referiam-se a Freire como o educador mais coherente do século XX, cujas lições deverão continuar válidas por muito tempo. Eles lançaram um "Manifesto" que assim se inicia: "No século que findou, dois projectos de sociedade fracassaram relativamente ao processo civilizatório: um porque privilegiou o eu, eliminando o nós; o outro porque privilegiou o nós, desconsiderando o eu. Neste novo século, confrontam-se dois projetos antagónicos de sociedade: um subordina o social ao económico e ao imperio do mercado; outro prioriza o social. Faz-se necessário construir um projeto de socidade onde o ser humano seja resgatado na sua plenitude de eu e nós, com base na 
prioridade do social sobre o económico. Para que este novo mundo seja possível, é necessário que a toda a humanidade entenda e aceite a educação transformadora como précondição. Esta educação tem como pressupostos o princípio de que ninguén encina nada a ninguém e que todos aprendem em comunhão, a partir da leitura coletiva do mundo". Não se pode entender o pensamento pedagógico de Paulo Freire descolado de um projeto social e político. Por isso, não se pode "ser freireano" apenas cultivando suas idéias. Isso exige, sobretudo, comprometerse com a construção de um "outro mundo possível”. Como dizia ele, na Pedagogia da autonomia (1997, p.86): "mundo não é um convite para transfórmalo.

Paulo Freire colocou o oprimido no palco da história, pelo seu engajamento político e pela sua teoria como contra-narrativa ao discurso dos poderosos e privilegiados. Ela valorizava, além do saber científico elaborado, também o saber primeiro, o saber cotidiano. Sustentava que o aluno não registra em separado as significações instrutivas das significações educativas e cotidianas. Ao incorporar conhecimento, ele incorpora outras significações, tais como como conhecer, como se produz e como a sociedade utiliza o conhecimento... enfim, o saber cotidiano do seu grupo social.

Uma noção que ele desenvolveu e que a distinguia atoda a conotação neolibleral, era noção de qualidade. Quando estava à frente da Secretaria Municipal de Educação de São Paulo ele nos falava de uma "nova qualidade". A qualidade é todos (quantidade) terem acesso ao conhecimento e a relações sociais e humanas renovadas. Qualidade é empenho ético, alegria de aprender. Para o pensamento neoliberal, a qualidade se confunde com a competitividade. O neoliberais negam a necesidades da solidariedade. Contudo, as pessoas não são competitivas, mas porque sabem enfrentar seus problemas cotidianos junto com os outros e não individualemente.

Uma outro contribuição de Freire à história das idéias pedagóficas é a sua concepção de currículo. Não se pode entender a pedagogia de Freire sem entender os conceitos de transdisciplinaridade, transcurricularidades e interculturalidade. A inter e a transdisciplinaridade freireanas não são apenas um método pedagógico ou uma atitude do profesor. Elas se constituem numa verdadeira exigência da própria natureza do ato pedagógico. Paulo Freire, na prática, sabia trabalhar com várias disciplinas ao mesmo tempo: a etnografía, a teoria literaria, a filosofía, a política, a economia, a sociologia, etc. Trabalhava mais com teorias do que com disciplinas ou currículos que dizia deveriam ser ultrapassados. Para o ato pedagógico concorrem muitas ciencias. Paulo Freire trabalhava ao mesmo também com várias perspectivas teóricas: a do militante político, do filósofo da libertação, do cientista, do intelectual, do revolucionario, etc.

Para mostrar a contribuição de Paulo Freire à pedagogia crítica gostaria de destacar alguns aspectos de sua teoria do conhecimiento e do seu conhecido "método".

1. A socidade brasileira e latinoamericana da década de 60 pode ser considerada como o grande laboratório onde se forjou aquilo que ficou conhecido como o "Método Paulo Freire". A situação de intensa mobilização política desse período teve uma importancia fundamental na consolidação do pensamento de Paulo Freire, cujas origens remontam à década de 50 . O momento histórico que Paulo Freire viveu no Chile foi fundamental para explicar a consolidação de seu pensamento político-pedagógico. No Chile, ele encontrou um espaço político, social e educativo muito dinámico, 
rico e desafiante, permitindo-lhe reestudar seu método em outro contexto, avaliá-lo na práctica e sistematizá-lo teóricamente.

Por outro lado, na constitução do seu método pedagógico, Paulo Freire fundamentava-se nas ciencias da educação, principalmente a psicologia e a sociologia; teve importancia capital a metodologia das ciencias sociais. A sua teoria da codificação e da de-codificação das palabras e temas geradores (interdisciplinaridade), caminhou passo a passo com o desenvolvimiento da chamada pesquisa participante.

O que chamou a atenção dos educadores e políticos da época foi a fato de que o método Paulo Freire "acelerava" o processo de alfabetização de adultos. Paulo Freire não estava aplicando ao adulto alfabetizando o mesmo método de alfgabetizaçã aplicado às crianças. É verdade, outros já estavam pensando da mesma forma. Todavía, foi ele o primeiro a sistematizar e experimentar um método inteiramente criado para educação de adultos.

De manera esquemática, podemos dizer que o "Métodos Paulo Freire" consiste en três momento dialéctica e interdisplinarmente entrelaçados:

a) A investigação temática pela qual aluno e profesor buscam, no universo ocabular do aluno e da sociedade onde ele vive, as palabras e temas centrais de sua biografia. Esta é a etapa da descoberta do universo vocabular, em que são levantadas palabras e temas geradores relacionados com a vida cotidianta dos alfabetizandos e do grupo social a que eles pertenecem. Essas palabras geradoras são seleccionadas em função da riqueza silábica, do valor fonético e principalemtne em função do significado social para o grupo. A descoberta desse universo vocabular pode ser efetuada a través de encontros informais com os moradores do lugar em que se vai trabalhar, convivendo como eles, sentido suas preocupações e captando elementos de sua cultura.

b) A tematização, pela qual profesor e aluno codificam e decodificam esses temas; ambos buscam o seu significado social, tomando assim conciencia do mundo vivido. Descobrem-se assim novos temas geradores, relacionados com os que foram inicialmente levantados. É nesta fase que são elaboradas as fichas para a decomposição das familias fonéticas, dando subsidios para a leitura e a escrita.

c) A problematização, na qual eles buscam superar uma primeira visão mágica por uma visão crítica, partindo para a transformação do contexto vivido. Nesta ida e vinda do concreto para o abstrato e do abstrato para o concreto, volta-se ao concreto problematizando-o. Descobrem-se assim limites e posibilidades existenciais concretas captadas na primeira etapa. Evidencia-se a necessidade de uma ação concreta, cultural, política, social, visando à superação de situações-limite, isto é, de obstáculos ao processo de hominização. A realidade opresiva é experimentada como um processo passível de superação. A educação para libertação debe desembocar na praxis transformadora.

Paulo Freire não ficou nessas primeiras intuições sobre o método. Ao longo de sua vida desenvolveu-o mesmo não queria que sua teoria de conhecimiento foie reducida a uma pura metodologia. Por isso não se pode destacar os passos do seu método sem entendê-los no contexto de sua epistemologia. Insisto ainda nesse ponto porque existem mitas leituras de Freire nas quais ele mesmo não se reconhecia, quer sejam leituras políticas dogmáticas, sectarias, quer sejam leituras pouco científicas e epistemologicamente pouco rigorsas. 


\section{Quais seriam, a meu ver, esses passos do seu "Método"?}

1. Ler o mundo. Paulo Freire insitiu a vida toda nesse conceito chave do seu pensamento. O primeiro passo do seu método de apropriação do conhecimeinto é a leitura do mundo. Aqui debe-se destacar a curiosidade como precondição do cohecimiento (interesse, para Habermas) É o aprendiz que conhece. Palabras geradoras, temas geradores, complexos temáticos, codificação, decodificação. No seu último livro Paulo Freire insistia ainda na autonomia do aluno. Dos seus primeiros aos últimos escritos procurou dar dignidade ao aprendente, respeitando a identidade do aluno. Ele não humilhava ninguém, nãó considerava o educador superior ao educando. Para ele jamais um educador poderia ser arrogante. Nada menos freireano do que um educador arrogante, prepotente. Ele tinha de intelectuais arrogantes, sobretudo de esquerda. Dizia que fazia parte da lógica da direita o intelectual ser arrogante, más na esquerda era uma deformação.

\section{Compartilhar a leitura do mundo}

lido. Não posso saber se minha leitura de mundo está correta a não ser que a compare como a leitura do mundo de outras pessoas. O diálogo não é apenas uma estratégia pedagógica. É um critério de verdade. A veracidade do meu ponto de vista, do meu olhar, depende do olhar do outro, da comunicação, da intercomunicação. Só o olhar do outro pode dar veracidade ao meu olhar. O diálogo com o outro não exclui o conflito. A verdade não nasce da conformação do meu olhar com o olhar do outro. Nasce do diálogo-conflicto com o olhar do outro.
O confronto de olhares é necessário para se chegar à verdade comum. Caso contrário a verdade a que se chega é ingênua, não crítica e criticizada. $\mathrm{O}$ meu está presente na busca da verdade. Esse segundo passo leva à solidaridade. O meu conhecimento só é válido quando eun o compartilho com alguém. Novamente a conhecimento só é válido quendo eu compartilho com alguém. Novamentea comparaçao com o pensamento de Habermas, que Paulo Freire tanto admirava: a ação comunicativa é parte da busca do conhecimento. Não é um ato generoso de compreensão humana do outro. É uma necessidade ontológica e epistemológica.

3. A Educação como ato de produção e de reconstrução do saber. Conhecer não é acumular conhecimentos, informa-oes ou dados. Conhecer implica mudança de atitude, saber pensar e não apenas assimilar conteúdos escolares do saber chamado universal. Conhecer é estabelcer relações, dizia Piaget e Paulo Freire completava: saber é criar vínculos. $\mathrm{O}$ conteúdo torna-se forma.Paulo Freire foi combatido pelos conteundistas iluministas porque eles não chegaram a entender que, em educação, a forma é o contúdo. Saber em educação é mudar de forma, criar a forma, formar-se. Educar-se é formar-se. Só muito recentemente os pedagogistas conseguiram entender essa nova visão da educação quando discutiram a educação do futuro, como no Relatório Jacques Delors da UNESCO (1998) onde ela está associada a quatro grandes pilares: aprender a aprender, aprender a fazer, aprender a viver juntos, aprender a ser. Pela primeira vez perceberma os especialistas em educação que educar é 
criar vínculos e não decorar conteúdos. Paulo Freire antecipou-se pelo menos 50 anos com o seu "Circulo de Cultura", criando uma metodología prática que oferece as bases para a construção desses pilares e rompendo com a noção clássica de "aula".

4. A Educação como prática da liberdade (libertação). Ate aquí creio que o construtivismo de Piaget também iria. Mas o construtivismo crítico de Paulo Freire foi além, afirmando a politicidade do conhecimento. É o momento da problematização, da existência pessoal e da sociedade, do futuro (utopia). Educação não é só ciência: é arte e práxis, ação-reflexão, conscientização e projeto. Como projeto a educação precisa reinstalar a esperança. Nada mais atual do que esse pensamento, numa época em que muitos educadores vivem alimentados mais pelo desencanto do que de esperança.

Não é fácil entender o pensamento de Pulo Freire. Ele não pode ser lido como qualquer outra litertura pedagógica, pois ele não queria escrever textos tecnicamente pedagógicos. Os textos de Paulo são também textos literários e devem ser lidos também como textos literários. Paulo fora professor de português na juventude e continuou durante toda a vida a apresentar seus textos de forma literária. Paulo Freire deu o manuscrito de seu último livro Pedagogía da autonomía para Ângela Antunes, directora pedagógica do Instituto Paulo Freire, em São Paulo, para uma revisão e introdução de títulos e intertítulos ao seu texto origina, antes de ser enviado para a publicação. Ângela, professora de portuguêz, fez sugest-es também de estilo. Por mais que ela argumentasse com Paulo Freire em favor de algumas dudan-as literárias, na disscusão final do texto, ele, em vários momentos, manteve sua primeira redação. Sua primeira redação era definitiva, mesmo que "inacabada", dizia ele. Ela era a expressão daquele momento; não era apenas científica, mas era também poética, literária. Paulo Freire reúne nos seus escritos o estilo literário, a linguagem científica e a linguagem poética. Não foi assim que foram escritos os grandes textos filosóficos?

2. A obra de Paulo Freire tem sido reconhecida mundialmente não apenas como uma resposta a problemas brasileiros do passado ou do presente, mas como uma contribuição original e destacada da América Latina ao pensamento pedagógico universal. Não se pode dizer que seu pensamento responda apenas à questão da educação de adultos ou à problemáitica do chamado "Terceiro Mundo". Creio que validade universal da teoria e da práxis de Paulo Freire está ligada sobretudo a quatro intuições originais:

1. Ênfase nas condições gnosiológicas da prática educativa. Toda obra de Paulo Freire está permeada pela idéia de que educar é conhecer, é ler o mundo para poder transformá-lo. Ele detacou, desde o início, a importância das metodologias, o que é muito atual. Foi acusado de não dar valor aos conteúdos e, por isso, de ser espontaneista e não-directivo. $\mathrm{Na}$ verdade ele não foi nada disso: seu pensamento estava fortemente orientado por um projeto político-pedagógico cujo conteúdo era a libertação. As críticas de espontaneísmo de não-directividade não procedem.

2. Defesa da educação como ato dialógico e, ao mesmo tempo, riguroso, intuitivo, imaginativo, afectivo. Paulo destaca a necessidade de uma razão dialógica comunicativa. A teoria do conhecimento de Paulo Freire reconhece que o ato de conhecer e de 
pensar estão directamente ligados à relação com outro. O conhecimento precisa de expressão e de comunicação. Não é um ato solitário. Além de ser um ato histórico, gnosiológico e lógico ele contém um quarto elemento que é a sua dimensão dialógica.

3. A noção de ciência aberta às necessidades populares ligada, portanto, ao trabalho, ao emprego, à pobreza, à fome, à doença etc. Seu método, por isso, não parte de categorias abstratas, mas dessas necessidades das pessoas, capturadas nas suas própirias expressões (valor da oralidade) e analisadas por ambos, educador e educando. Nos últimos anos Paulo Freire destacou também as necesidades planetárias trazidas ao debate pela ecologia, como nesessidades humanas, fundamentais, ligadas por exemplo, ao saneamento básico, ao lixo, à água, à poluição do ar. Dia 17 de abril de 1997, poucos dias antes de flecer, ele falva de ecopedagogia, afirmando que amava a Terra, os bichos, as plantas. Dizia ele numa entrevista dada no Instituto Paulo Freire naquele dia: "Quero sem lembrado como alguém que amou os homens, al mulheres, as plantas, os animais, a Terra". Um dos seus últimos livros foi $A$ sombra desta mangueira onde ele fala do prazer de respirar ar puro (uma das necessidades humanas), de entrar num rio despoluído, de pisar na grama, na areia da praia. E criticava a lógica capitalista que não valoriza esses prazeres gratuitos e por substituí-los por prazeres vendidos e comprados, prazeres que dão lucro. $\mathrm{O}$ capitalismo tem necessidade de substituir felicidades gratuitas (necessidades humanas) por felicidades vendidas e compradas, que são, acima de tudo, necessidades do capital e, muitas vezes, não são necessidades hu- manas; são necessidades impostas aos seres humanos, com a finalidade do lucro.

4. O planejamento comunitário, participativo, a gest-o democrática, a pesquisa participante. Sob influência do pensamento de Paulo Freire hoje no Brasil estão se realizando muitas experiências educacionais de enorme impacto, relacionadas com a chamada "Constituinte Escolar", que utiliza os princípios metodológicos freireanos e com o emblemático "Orçamento Participativo" no quadro no movimiento pela Escola Cidadã, outra expressão tambén utilizada por ele nos últimos anos.

O reconhecimiento de Paulo Freire fora do campo da pedagogia, demonstra que o seu pensamento é tambén transdisciplinar e transversal. A pedagogia é essencialmente uma ciência transversal. Desde seus primeiros escritos considerou a escola muito mais do que a quatro paredes da sala de aula. Criou o "Círculo de Cultura", como expressão dessa nova pedagogia que não se reduzia à noção simplista de "aula". Na sociedade do conhecimento de hoje isso é muito mais verdadeiro já que o "espaço escolar" é muito maior doque a escola. Os novos espaços da formação (mídia, rádio, TV, vídeo, igrejas, sindicatos, empresas, ONGs, espaço tornou-se comunitária, virtual, multiculral e ecológica e a escola estendeu-se para a cidade e o planeta. Hoje se pensa em rede, se pesquisa em rede, trabalha-se em rede, sem hierarquias. A noção de hierarquia (saber-ignorãncia) é muito cara à escola capitalista. Ao contrário, Paulo Freire insista na conectividae, na gestão coletiva do conhecinento social a ser socializado de forma ascendente. Não se trata mais de ver apenas a "cidade educativa" (Edgar Faure) mas de enxengar o planeta como uma escola permanente. 
Abrir a escola para o mundo, como queria Paulo Freire, é uma das condições para a sua sobrevivêcia com dignidade, nessa travessia de milênio. O novo espaço paradigma escolar é o planeta porque a Terra tornou-se nosso endereço, para todos. $\mathrm{O}$ novo paradigma educativo funda-se na condição planetária da existência humana. A planetaridade é uma nova categoria que fundamenta o paradigma Terra, isto é, a visão utópica da Terra como um organismo vivo e em evolução, onde os seres humanos se organizan como uma única comunidade, compatilhando a mesma morada com outros seres e coisas.

\section{As perspectivas atuais da edu-} ção estão marcadas hoje pela questão do conhecimento. E não é por acaso. O conhecimento tornou-se peça chave para entender a própria sociedade atual. Fala-se em sociedade do cohecimetno, às vezes com impropriedade. Mais doque a era do conhecimetno devemos dizer qie vivemos a era da informaço, pois percebemos com mais facilidade a disseminação da informaço e de dados, muito mais do que de conhecimentos. $\mathrm{O}$ acesse ao conhecimento é ainda muito precário, sobretudo em sociedades comgrande atraso educacional como a nossa.

\section{Hoje as teorias do conhecimento} na educação estão centradas na aprendizagem. Partindo do pensamento freireano, podemos afirmar pelo menos sete teses sobre a construção do cohecimento.

1. O que é conhecer? É construir categorías de pensamento, dizia Piaget. É ler o mundo e transformá-lo, dizia Freire. Conhecer é tudo isso -construção de categorías de pensamento, ler o mundo, transformar o mundomesmo porque não é possível construir categorías de pensamento como se elas existiessem a priori, independentemente do sujeito que, ao conhecer, reconstrói o que conhece.
2. Como se conhecer? Só é possível conhecer quando se deseja, quando se quer, quando nos evolvemos profundamente no que apreendemos. No aprendizado, gostar é mais importante do que criar hábitos de estudo, por exemplo. Hoje se dá mais importância às metodologias da aprendizagem, às linguagens e às línguas, do que aos conteúdos. A transversalidade e a transdisciplinaridade do conhecimento é mais valorizada do que os conteúdos longitudinais do currículo clássico.

3. O que conhecer? Frente à disseminação e à generalização do conhecimento é necesario que a escola e o professor, a profesora, façam uma seleção crítica, pois há muito lixo e propaganda engañosa sendo veiculados. Não faltam, também na era da informação, encantadores da palabra para tirar algum proveito, seja econômico, seja religioso, seja ideológico.

4. Por que conhecer? Conhecer é importante porque a educação se funda no conhecimento e o conhecimento na atividade humana. Para innovar é preciso conhecer. A atividade humana é intencional, não está separada de um projeto. Conhecer não é só adaptar-se ao mundo. É condição de sobrevivência do ser humano e da espécie, como diz Habermas.

5. Conhecimento e intesse. Antes de conhecer o sujeito se interessa por (Habermas), é curioso (Freire), é esperançoso (Ernst Bloch). Daí a importância do trábalo de sedução do professor, da profesora, frente ao aluno, à aluna. Daí a necesidades da motivação, do encantamento. É preceiso mostrar que "aprender é gostoso, mas exige esforço", como dizia Paulo Freire no primeiro documento que 
encaminhou aos profesores quando assumiu a Secretaria de Educação do Municipio de São Paulo.

6. Todos podem conhecer. Ninguém sabe tudo, niguém ignora tudo. Todos nos educamos em comunhão (Freire).

7. Só é cohecimento válido o conhecimento compartilhado. (Método Paulo Freire).

Nós educadores sentimos falta ainda de outras teses, teses que nos ajudem a entender $o$ ato de aprender, para entendernos melhor o ato de encinar. Para nós educadores não basta saber como se constrói o conhecimento. Nós precisamos dominar outros saberes da nossa difícil tarefa de encinar. Precisamos saber o que é e, sobretudo, como aprender. As teses a seguir foram tiradas de múltiplas vivências, seja da minha prática, seja de teóricos que estudei, mas sobretudo da convivência de 23 anos com Paulo Freire. Aprendi dele mitas lições. Tivemos oportunidade, com freqüência, de trocar idéias sobre isso. Paulo, como educador, estava preocupado constantemente com o ato de aprender, de escuchar, de encinar. Reuno aquí pelo menos sete teses sobre esse tema.

1. Aprendemos a vida toda. Não há tempo próprio para aprender.

2. Aprender não é acumular conhecimentos. Aprendemos histórica não para acumular conhecimentos, datas, informações, mas para saber como os seres humanos fizeram a histórica para fazermos história.

3. O importante é aprender a pensar. (a realidade, não pensamentos), aprender a aprender.

4. É o sujeito que aprende a través da sua experiência. Não é um coletivo que aprende.
5. Aprende-se que é significativo para o projeto de vida da possoa. Aprende-se quando se tem um projeto de vida.

6. É preciso tempo para aprender e para sedimentar informações. Não dá para injetar dados e informações na cabeça de ninguém. Exige-se também disciplina e dedicação.

7. "Quem encina aprende ao encinar e quem aprende encina ao aprender" (Paulo Freire, Pedagogía da autonomia, 1997, p. 25).

O conhecimento tem hoje um peso diferente do que tinha na era da industria. Vivemos numa época de desconforto, de desasossego. A modernidade nos fez muitas promesas que não froram cumpridas, nos diz Boaventura Santos em seu livro Pela mão de Alice. O trábalo desmaterializou-se. Saber fazer hoje tornou-se, por isso, mais cognitivo do que instrumental. Não basta aprender, pois o conhecimento é polivalente. Importa muito mais aprender a aprender $e$ aprender a viver juntos, a participar em projetos comuns. Aprender tornou-se sobretudo fazer uma grande viagem ao interior do ser, com autonomia, $s a$ ber cuidar de si, dos outros, das coisas, esses três "grandes mestres" de que nos fala Rousseau no primeiro livro do seu Emílio. Mais importante do que saber é nunca perder a capacidade de aprender.

4. O que mais preocupava Paulo Freire nos últimos anos era avanço de uma globalização capitalista neoliberal. Por que ele atacava tanto o pensamento e a práctica neoliberal? Por que o neoliberlismo é visceralmente contrário ao núcleo central do pensamento de Paulo Freire que é a utopia. Enquanto o pensamento freireano é utópico o pensamento neoliberal abomina o sonho. Para Paulo Freire o futuro é possibilidade. Para neoliberalismo o futuro é 
fatalidade. O neoliberalismo apresenta-se como única resposta à realidade atual, desqualificando qualquer outra proposta. Desqualifica principalmente o Estado, os Sindicatos e os Partidos Políticos. Denuncia a política fazendo política. Paulo Freire atacava a ética do mercado sustentada pelo neoliberalismo, porque ela se baseia na lógica do controle e afirmava uma ética integral do ser humano. No seu livro Pedagogia da autonomia (p. 15) ele destacaba: "Daí a crítica permanentemente presente em mim à malvadez neoliberal, ao cinismo de sua ideologia fatalista e a sua recusa inflexível ao sonho e è utopia. Daí a minha raiva, legítima raiva, que envolve a meu discurso quando me refiro ás injustiças a que são submetidos os esfarrapados do mundo. Daí o meu nenhum interesse de, não importa que ordem, asumir um ar de observador imparcial, objetivo, seguro, dos fatos e dos acontecimentos. Em tempo algum pude ser um observador "acinzentadamente" imparcial, o que porém, jamais me afastou de uma pisição rigoriosamente ética" O anti-academicismo de Freire é conhecido. E assim termina o mesmo livro (p.165): Nem a arrogância é sinal de competência nem a competência é causa da arrogância. Não nego a competência, por outro lado, de certos arrogantes, mas lamento neles a ausencia da simplicidade que não diminuindo em nada seu saber, os faria gente melhor. Gente mais gente.

A educação não pode orientar-se pelo paradigma da empresa que dá ênfase apenas à eficiencia. Este paradigma ignora o ser humano. Para este paradigma, o ser humano funciona apenas como puro agente econômico, un "fator humano". O ato pedagógico é democrático por natureza, o ato empresarial orienta-se pela "lógica do controle". O neoliberalismo consegue naturalizar a desigualdade. "É assim mesmo", "Não há outra coisa a fazer", ouve-se dizer. Por isso, Paulo Freire chama nossa atenção para a necessidade de observarmos o processo de construção da subjetividade democrática, mostrando, ao contrário, que a desigualdade não é natural. É preciso aguçar nossa capacidade de estranhamento. Precisamos ter cuidado com a anestesia da ideologia neoliberal: ela é fatalista, vive de um discurso fatalista. Mas não há nenhuma realidade señora dela mesma. O neoliberalismo age como se a globalização foie uma realidade definitiva e não uma categoría histórica.

A concepção de mundo e a sua teoria sócio-plítico-educativa nos ajudam não apenas a entender melhor como funciona o modelo neoliberal, mas nos ajudam a construir a resposta necesaria ao neoliberlismo. Ele defende uma nova modernidade cuja racionalidade debe estar "molhada de afetividade". Contra o iluminismo pedagógico e cultural que acentua apenas a aquisição de conteúdos curriculares, ele realça a importância da dimensão cultural nos processo de transformadora - transformar as condições de pressão-ela debe enraizar-se na cultura dos povos. A pós-modernidade se caracteriza pelo simulacro e pelo consumo imediato. Ora, a educação é um processo a longo prazo e precisa combater o imediatismo, o consumismo, se quiser contribuir para a construção de uma pós-modernidade progresista. A educação, para ser libertadora, precisa construir entre educadores e educando uma verdadeira conciência histórica. $\mathrm{E}$ isso demanda tempo.

\section{Certos críticos conservadores} afirman que ele não tem uma teoria do conhecimento porque não estuda as relações entre o sujeito do conhecimento e o objeto. Ele se interesaría apenas pelo produto. Isso não é verdade: antes de mais nada, o seu pensamento funda-se numa explícita teoria antropológica do conhecimento. Outros o acusam de autoritarismo afirmando que o seu método supõe a 
transformação da realidade e nem todos desejam transformá-la. Por tanto, seria um método não científico (porque não aplicable universalmente). Seu método seria autoritario na medida em que ele obriga a todos a participarem na transformação. É claro que essa crítica ignora que Paulo Freire não aceita a ideéia de uma teoria pura -para ele uma iluão- mas numa teoria crítica enraizada numa filosofia social e política. Ele rejeita a idéia da neutralidade científica -como recusa o academicismo- e argumenta que os conservadores, sobre a capa da neutralidade política de uma teoria pura esconden a sua idelogia conservadora.
Paulo Freire deixou um grande legado que hoje atravessa, cruza e rompe fronteiras. Nessa travesía de milênio seu pensamento resurge e se renova em innumeras experiências de educação popular, de educação continuada e informal, em escolas públicas e privadas, em políticas públicas, em diversas áreas do conhecimento, em diferentes profissões, confrontando-se com diferentes práticas e teorias. É um pensamento vivo e em evolução. Por isso não se trata de fazer uma leitura exegética do ele escreveu. Trata-se de dar continuidade e de reinventar, na prática, as grandes intuições e motivações político-pedagógicas que orientaram seu pensar militante. 